\title{
Mediação bibliotecária no desenvolvimento de competências durante estágio supervisionado
}

\author{
Maria Josélia de Oliveira \\ j.joselia.oliveira@gmail.com \\ Maria Giovanna Guedes Farias \\ Universidade Federal do Ceará, Departamento de Ciência da Informação, Fortaleza, CE, Brasil \\ mgiovannaguedes@gmail.com
}

DOI: https://doi.org/10.26512/rici.v13.n1.2020.24444

Recebido/Recibido/Received: 2019-05-01

Aceitado/Aceptado/Accepted: 2019-12-03

Resumo: Apresenta resultados de pesquisa desenvolvida com o objetivo de analisar o papel do bibliotecário na formação do estudante de Biblioteconomia durante o estágio supervisionado, como mediador no desenvolvimento de competências que atendam às exigências do mercado de trabalho. Trata-se de investigação guiada pela abordagem qualitativa, com método de pesquisa exploratória. Para coleta dos dados se fez uso de questionário e roteiro de entrevista, e os dados foram analisados pela técnica de análise de conteúdo com o estabelecimento de categorias. Os resultados demonstram que a participação do bibliotecário como orientador técnico representa uma chave de acesso ao mercado, sendo um mediador ativo dessa passagem academia-mercado. Para isso, a network que se forma nos estágios deve ser considerada como a célula geradora de relações profissionais que podem contribuir com o desenvolvimento ou aprimoramento das competências de quem já está no mercado e de quem ainda vai chegar, através da contínua troca de experiências. Concluímos que o estágio supervisionado é uma ponte entre academia e sociedade, e o bibliotecário é o mediador, que pode contribuir tanto no desenvolvimento das competências técnicas inerentes às rotinas diárias da profissão, quanto nas competências comportamentais, e que a mediação bibliotecária perpassa a orientação técnica, tornando-se uma ação dialógica entre os sujeitos (orientador técnico e estagiário) que constroem uma relação sedimentada na troca de experiências.

Palavras-chave: bibliotecário. mediação. estágio supervisionado. competências.

\section{Library mediation in the development of competences during supervised stage}

Abstract: It presents results of research developed with the objective of analyzing the role of the librarian in the training of the Librarianship student during the supervised stage, as mediator in the development of competences that meet the demands of the labor market. This is research guided by the qualitative approach, with an exploratory research method. Data were collected using a questionnaire and interview script, and the data were analyzed using the content analysis technique with the establishment of categories. The results demonstrate that the librarian's participation as a technical advisor represents a key access to the market, being an active mediator of this marketacademia pass. For this, the network that is formed in the stages should be considered as the cell that generates professional relationships that can contribute to the development or improvement of the skills of those who are already in the market and who will still reach, through the continuous exchange of experiences. We conclude that the supervised internship is a bridge between academy and society, and the librarian is the mediator, who can contribute both to the development of the technical skills inherent to the daily routines of the profession and to the behavioral competences, and that library mediation goes beyond the technical orientation, becoming a dialogical action between the subjects (technical advisor and trainee) that build a sedimented relationship in the exchange of experiences.

Keywords: librarian. mediation. supervised internship. skills. 
Mediación de la biblioteca en el desarrollo de competencias durante pasantías supervisadas

Resumen: Presenta los resultados de la investigación desarrollados para analizar el papel del bibliotecario en la formación del estudiante de la Bibliotecología durante la pasantía supervisada, como mediador en el desarrollo de habilidades que satisfagan las demandas del mercado laboral. Es una investigación guiada por el enfoque cualitativo, con método de investigación exploratoria. Para la recolección de datos, se utilizó un cuestionario y un guion de entrevista, y los datos se analizaron mediante la técnica de análisis de contenido con el establecimiento de categorías. Los resultados muestran que la participación del bibliotecario como asesor técnico representa una clave para el acceso al mercado, ya que es un mediador activo de este pasaje de la academia al mercado. Para esto, la red que se forma en las pasantías debe considerarse como la célula generadora de relaciones profesionales que pueden contribuir al desarrollo o la mejora de las habilidades de quienes ya están en el mercado y quienes llegarán, a través del intercambio continuo de experiencias. Concluimos que la pasantía supervisada es un puente entre la academia y la sociedad, y el bibliotecario es el mediador, que puede contribuir al desarrollo de las habilidades técnicas inherentes a las rutinas diarias de la profesión, así como a las competencias conductuales, y que la mediación de la biblioteca va más allá de la orientación técnica. , convirtiéndose en una acción dialógica entre los sujetos (asesor técnico e interno) que construyen una relación sólida en el intercambio de experiencias.

Palabras clave: bibliotecario. mediación. prácticas supervisadas. habilidades.

\section{Introdução}

Diante desse complexo panorama social, a vida discente na universidade se efetiva sob várias facetas onde, almejando formar o bibliotecário, são apresentadas ferramentas próprias para o ofício, sem olvidar o objetivo de formar o indivíduo para o convívio social de forma equilibrada e colaborativa na construção de uma sociedade mais igualitária. Para tanto, são oferecidas oportunidades de ensino, pesquisa e extensão, possibilitando visões da sociedade para além dos espaços circunscritos da academia. Essas oportunidades são complementadas no curso de Biblioteconomia com o Estágio Supervisionado Obrigatório (ESO), onde o discente tem a oportunidade de vivenciar a realidade do mercado, tendo como tutor o bibliotecário, denominado de orientador técnico.

Destarte, realizamos esta pesquisa visando tratar das questões imbricadas nessa relação construída durante o processo de formação profissional no ESO, momento em que ocorre a mediação do bibliotecário, o qual contribui na construção de competências dos discentes, que são exigidas pelo mercado de trabalho. Há uma considerável produção de relatos de experiências discentes a partir da prática desenvolvida durante o estágio supervisionado, contudo, esta pesquisa se concentra na percepção da efetiva contribuição do bibliotecário no papel de orientador técnico do estágio e sua colaboração para que o estagiário se sinta apto a enfrentar o mercado.

O estágio supervisionado é uma etapa prevista pelo Conselho Nacional de Educação (CNE) nas Diretrizes Curriculares Nacionais e componente obrigatório no curso de Biblioteconomia da Universidade Federal do Ceará (UFC). Constitui-se como uma etapa fundamental na formação do discente considerando que, o bibliotecário responsável por 
orientá-lo, exercerá influência no que se refere à atuação futura do discente no mercado, bem como na postura deste, diante de diversas situações durante o exercício da profissão.

A justificativa para realização desta pesquisa vai ao encontro do pensamento de Targino (2006), ao ressaltar que o bibliotecário deve, ao exercer sua profissão, se preocupar com a dimensão social da biblioteca e, consequentemente, do usuário. Deste modo, esta investigação objetivou identificar a ação mediadora do bibliotecário como orientador técnico no desenvolvimento de competências do discente durante o estágio supervisionado. Os pressupostos metodológicos tiveram como foco a abordagem qualitativa, aplicada a uma pesquisa em nível exploratória. Para coleta de dados, utilizamos a entrevista semiestruturada, aplicada a uma amostra intencional de bibliotecários que estivessem vivenciando a atividade profissional no mercado de trabalho.

Diante da dificuldade em trabalhar com todo o marco referencial, optamos por um recorte do público-alvo representado por profissionais em plena atividade laboral na área, constituído por egressos de 2005 e de 2015. A escolha por tal amostra se deu por considerar um intervalo temporal de dez anos, significativo para detectar diferentes perspectivas entre a formação acadêmica e as exigências mercadológicas. Além disso, a média de dez anos de atuação profissional, daqueles que se formaram em 2005 possibilitou-os vivenciar diferenças sociais e tecnológicas ocorridas na área.

\section{Bibliotecário como orientador técnico}

Desempenhar um papel de orientador técnico exigirá do bibliotecário uma carga extra de trabalho, considerando que suas tarefas rotineiras continuam em pauta, enquanto $o$ orientando necessita de atenção especial para que as atividades não sejam desempenhadas de forma automática e até errônea por inaptidão do desenvolvimento das atividades propostas, acarretando danos no desenvolvimento posterior das rotinas no ambiente.

Compreendemos assim, que não basta a disposição do bibliotecário em receber um estagiário no seu ambiente de trabalho, ele assume também o compromisso com o papel de educador, no que tange à concretização por parte do aprendiz das teorias ministradas pelo docente em sala, em forma de atividades práticas exigidas no desenvolvimento do "fazer técnico". Para tanto, o orientador técnico desempenha o papel de mediador, nessa transição entre teoria e prática. Essa troca de experiências é vital para que o discente ratifique as relações entre as teorias e as ações ocorridas no ambiente informacional onde atua. Experiências que poderão fortalecer o diálogo entre academia e sociedade, além de contribuir com o profissional ao lhe possibilitar atualização com as percepções construídas na academia. 
A mola propulsora dessa construção é o diálogo aberto, uma postura ética diante da realidade e das dificuldades dos envolvidos nesse processo da orientação técnica como parte valiosa da graduação. Silva e Farias (2017) ao descreverem diversos tipos de mediação ressaltam conexões entre elas apontando que apesar de:

[...] contradições e complementos, a lógica mais proficiente é a de que são interligadas como atividades holísticas e estratégicas no sentido de que a mediação da informação precisa do institucional para se estabelecer estrutural e gerencialmente, além do técnico e pedagógico para se estabelecer no caráter social e pragmático dos sujeitos (comunidade de usuários) envolvidos na mediação da informação [...] (SILVA; FARIAS, 2017, p. 111).

Ou seja, a complexidade das relações sociais se manifesta também nas construções conceituais, não sendo possíveis definições absolutas e limitantes para questões interdependentes das percepções e atitudes coletivas dos sujeitos envolvidos em suas construções, logo mediar é um verbo que exige o complemento do encontro e da partilha com o outro.

O bibliotecário na orientação técnica mediatiza o desenvolvimento de competências no discente, entretanto, se faz necessário uma participação ativa do estagiário, ratificando o entendimento de que a mediação "[...] antes de se tornar função, ela foi uma relação social entre duas pessoas [...]" (FARIAS, 2016, p. 120), uma relação social construída entre bibliotecário e o estagiário sob sua orientação, durante o estágio.

É importante ressaltar que a contribuição do bibliotecário é fundamental no desenvolvimento de competências do profissional em formação. Todavia, o essencial é a proatividade discente que vem sendo proposta desde seu ingresso na universidade, onde ele é convidado constantemente a empoderar-se do seu desenvolvimento intelectual, cognitivo e social. Assim, ser proativo é assumir uma nova postura diante das possibilidades de aprendizagem.

Caso o discente tenha assumido o compromisso com a própria formação desde o início no seu percurso na academia, apresentar-se-á no ambiente laboral de forma ética e profissional, com atitude de profícuo interesse em colaborar com o seu orientador, interagindo de forma comprometida com a aprendizagem e com as atividades propostas, buscando nesse processo aprender com as experiências de quem está no mercado.

Logo, fazer esse trajeto com a participação colaborativa de um orientador competente e prestativo na arte de guiar, certamente evitará tropeços no desenvolvimento das atividades futuras. É certo que, esse momento exigirá desse orientador além de competências, a consciência da sua responsabilidade na formação do profissional que está em 
desenvolvimento. Uma mediação pedagógica e comportamental agregando conhecimentos técnicos e cognitivos que perpassarão o período de formação acadêmica, consciente que:

[...] mediar o conhecimento, com objetivo de promover o desenvolvimento do protagonismo social por meio de competências em informação, requer do mediador autoconhecimento profissional, tendo em mente que todas as ações devem ser realizadas sempre em conjunto, e de forma dialógica com todos os sujeitos envolvidos [...]. (FARIAS, 2016, p. 107).

É imprescindível assim, o diálogo almejando a troca de saberes e vivências práticas e acadêmicas entre aprendiz e profissional possibilitando uma etapa significativa na construção de competências que resultarão no bom desempenho profissional no futuro. Todavia, para que aconteça essa dialética de saberes, primeiramente é preciso saber quais competências o bibliotecário possui e que podem ser apresentadas ao discente no decorrer do estágio, para que este desenvolva suas habilidades, consciente de quais competências o mercado tem exigido desse profissional.

Desenvolver competências é um processo de construção onde o indivíduo precisa estar atento ao contexto para captar as necessidades, os anseios e as possibilidades de contribuir com a satisfação dessas. Esse processo deve começar a ser moldado a partir dos discursos acadêmicos, possibilitando a concretização nas práticas além da universidade.

Ao desempenhar o papel de orientador técnico, o bibliotecário contribui com o orientando no desenvolvimento das competências técnicas, no entanto, as comportamentais ficam na tênue questão da mediação definida por Paulo Freire (1987) como uma questão "dialógica", ou seja, algumas questões dependem quase exclusivamente do sujeito em formação. A criatividade é um exemplo real dessa dependência do esforço próprio para o seu desenvolvimento. A flexibilidade também é uma competência desenvolvida a partir da maturidade de cada indivíduo sedimentada nas vivências de cada um. Logo, entendemos que a contribuição do bibliotecário na formação discente é vital, mas não o isenta da proatividade nesse processo, ou seja, o interesse próprio em buscar, questionar e colocar-se à disposição de uma aprendizagem colaborativa que desencadeará o enriquecimento da própria formação.

Ao tratar especificamente das competências basilares ao profissional da informação, Barbalho (2004, p. 5) apresenta seis tipos de competências delineadas no estudo de Vendrell e Miranda (1999): intelectual, prática, interativa, social, éticas e estéticas.

Nesta perspectiva, entendemos que o discente precisa se empenhar no desenvolvimento das competências destacadas por Vendrell e Miranda (1999) citadas por Barbalho: competência intelectual requer conhecimento construído nas leituras e interpretações de mundo do sujeito cognoscente; competência prática dependerá das contribuições sociais, mas também da proatividade no desenvolvimento de atividades 
proposta; competências ética e estética requerem além do comportamento social adequado ao meio um senso crítico intersubjetivo no que compete à questões imensuráveis que fogem da arte de ensinar, mas são inerentes ao ser, na concepção de distinguir questões metafísicas (Quero? Posso? Devo?); competência interativa (capacidade de conviver em grupo); competência social (capacidade de liderar e ser subordinado); essas duas últimas dependem das relações construídas desde o seio familiar, comunidade acadêmica e profissional, respeitando as diferentes ideias e comportamentos sociais.

Ao cotejarmos as concepções dos autores acima podemos identificar algumas semelhanças entre as competências técnicas de Leme (2005) equivalente às competências práticas descritas por Vendrell e Miranda (1999), bem como as competências: ética, estética, interativa e social correspondentes às competências comportamentais definidas por Leme, o que demonstra consonâncias entre os conceitos.

As relações construídas entre estagiário e bibliotecário, podem contribuir no desenvolvimento de tais competências ao mostrar ao discente, na prática, que a dinamicidade das competências exigidas varia de acordo com os papéis a desempenhar dentro de uma unidade informacional, como descreve Barbalho (2004, p. 7):

\begin{abstract}
Administrador/planejador - formulador de políticas de condução e ação; gestor dos recursos e coordenador do processo de avaliação dos resultados a partir das políticas institucionais; Técnico - processador, analista e preparador da informação requerida pelo usuário, conforme as políticas institucionais; Assessor - difusor da informação; Autônomo - utilizador dos novos espaços que o mercado oferece [...] (BARBALHO, 2004, p. 7)
\end{abstract}

Para atender a tais perfis o bibliotecário necessita mais que competências técnicas e comportamentais; precisará desenvolver a competência em informação, a qual, segundo Farias e Belluzo (2015), é a capacidade de reconhecer a necessidade da informação, saber identificá-la, e usá-la de forma responsável e proveitosa. Destarte podemos considerar tal competência primordial a qualquer profissional, para o bibliotecário, no entanto, torna-se imprescindível, considerando as facilidades de acesso possibilitadas pelas inúmeras ferramentas que a tecnologia e o uso maciço da internet dispõem aos usuários da informação. Se antecipar, detectando necessidades e possibilidades de uso pode ser um grande diferencial no mercado.

Precisamos compreender, porém que a competência em informação requer mais do que a tríade do CHA, conhecimento (saber), para desenvolver habilidades (saber o que fazer como agir) exige uma prática, que pode ser construída, diretamente com a contribuição do bibliotecário orientador durante o estágio supervisionado, e que atitude é a única das características que depende exclusivamente do discente. A participação ativa do bibliotecário 
e do estagiário é fundamental para a construção de competências do aprendiz, não havendo um único responsável para tanto, mas um processo de construção conjunta com contribuições e responsabilidades inerentes a ambos os protagonistas desse processo. 0 estagiário ainda deve mostrar-se interessado, indagando sobre o que considerar necessário para a melhoria das ações que realiza na unidade de informação. Dessa forma, poderá atender as expectativas de aprendizagem exigidas durante o ESO.

Nesta perspectiva, compreendemos que mediar envolve a construção de competências, de anseios e percepções múltiplas que afetam diretamente no perfil de um profissional em formação, que almeja adentrar no mercado trabalho competitivo, exigente e cada dia mais imprevisível. Dessa forma, para saber quais competências são desenvolvidas a partir dessa relação de interferência mútua, primeiramente é necessário traçar um perfil do bibliotecário, para saber quais competências Ihe são exigidas já que:

[...] em termos organizacionais a competência concentra-se na análise da contribuição do indivíduo para a organização, bem como o modo como ela é concretizada, exigindo-se assim, não uma competência, mas um conjunto delas que envolve tanto um saber geral, quanto um conhecimento específico para o exercício da atividade (BARBALHO, 2004, p. 2).

Em tempos de intensas possibilidades de acesso à informação de forma remota, rápida e ilimitada, o leque de competências se amplia para todo profissional, para o bibliotecário, no entanto, se torna um requisito básico acompanhar as novidades oferecidas pelos avanços tecnológicos e diante da impossibilidade de aprender tudo, a troca de experiências pode agregar valor para os sujeitos envolvidos em âmbitos social, institucional e pessoal.

\section{Procedimentos metodológicos}

A pesquisa se constrói, portanto, na tentativa de desvendar as percepções dos sujeitos envolvidos quanto às contribuições do bibliotecário como orientador técnico no desenvolvimento de competências necessárias para atender às exigências do mercado e, para tanto, há de ser desenvolvida dentro do contexto social onde estão inseridos tais sujeitos.

Tendo esta pesquisa o objetivo de vivenciar os ambientes e as percepções dos sujeitos que os constroem, entendemos que a abordagem qualitativa é a mais adequada na construção desse processo. Nesse cenário natural, onde ocorrem as atividades cotidianas dos sujeitos pesquisados é que se desenvolveu o contato interpessoal, entre entrevistadora e entrevistados, buscando captar as mensagens subliminares dos discursos não explicitados. Farias (2014, p. 111) corrobora nossa ideia de conhecer o ambiente e seus atores quando se pretende aplicar a pesquisa qualitativa. 
Trata-se de pesquisa de nível exploratória tendo "como principal finalidade, desenvolver, esclarecer e modificar conceitos e ideias, tendo em vista a formulação de problemas mais precisos, ou hipóteses pesquisáveis para estudos posteriores" (GIL, 1999, p. 27), ou seja, a pesquisa nesse nível é utilizada nos primeiros passos de quem almeja ambientar-se com o objeto de estudo intentando o aprofundamento em estudos posteriores. Nessa perspectiva, buscamos alcançar os objetivos propostos quanto às competências técnicas, comportamentais e informacionais desempenhadas pelo bibliotecário no mercado de trabalho e como ele desenvolve tais qualificações.

Para coleta dos dados utilizados na pesquisa foi aplicada a entrevista semiestrutura, entendendo sua adequação como instrumento que possibilita o respeito às singularidades dos sujeitos pesquisados, permitindo, contudo, um rumo no sentido dos objetivos propostos.

O uso da entrevista semiestrutura se materializa através de um roteiro, dando aos sujeitos (pesquisador e entrevistado) a possibilidade de uma interação, considerando que o "entrevistado tem a possibilidade de discorrer sobre o tema em questão sem se prender à indagação formulada" (MINAYO, 2013, p. 64).

Foi desenvolvida também uma nota explicativa, com o intuito de ambientar os entrevistados aos conceitos aplicados na pesquisa e um questionário complementar. Tais instrumentos foram aplicados com o intuito de não desviar o foco almejado, e possibilitar a flexibilidade para um diálogo mais interacionista. Respeito e discernimento para entender o tempo e o espaço de cada sujeito, possibilitaram um diálogo aberto e enriquecedor quanto à contribuição do entrevistado buscando um resultado claro e objetivo.

Para analisar os dados, utilizamos a técnica de análise de conteúdo ( $A C)$, pois consideramos essa técnica ideal para subsidiar um resultado mensurável entre discurso e ação dos sujeitos, conforme Bardin (1977).Definimos as seguintes categorias de análise:

a) Visão do bibliotecário quanto à relevância do estágio supervisionado no desenvolvimento de competências - captar o olhar dos profissionais sobre o nível de significância do estágio para a formação profissional, e como essa etapa na vida acadêmica influenciou sua própria formação profissional;

b) Competências que foram desenvolvidas durante o estágio supervisionado as competências técnicas, comportamentais, competência em informação, são desenvolvidas em menor ou maior grau nos diversos âmbitos da vida; essa categoria aborda o que foi possível desenvolver nesse período de que forma contribuiu para a vida pós-academia;

c) A influência do bibliotecário no desenvolvimento de competências buscamos neste item identificar o resultado da ação desse profissional para a formação do perfil profissional dos entrevistados, ou seja, como o orientador (bibliotecário) serviu de referencial para o desempenho profissional do entrevistado;

d) A perspectiva bibliotecária quanto às competências exigidas pelo mercado de trabalho - nesta categoria objetivamos identificar o ponto de vista de quem já 
vivencia a realidade profissional sobre quais as competências exigidas no mercado para quem intenta atuar como bibliotecário. Diante de uma vasta lista de exigências, buscamos detectar as principais competências a serem apresentadas do ponto de vista dos participantes.

Para responder a cada categoria, selecionamos os sujeitos da pesquisa, bibliotecários que estão em plena atividade no mercado de trabalho, independente da área de atuação (arquivo, bibliotecas ou outros ambientes informacionais). Assim, o público-alvo foi delimitado a profissionais que se formaram no ano em Biblioteconomia pela UFC em 2005 e em 2015. Nesse recorte temporal dos sujeitos almejamos captar diferentes perspectivas dos dois grupos, quanto ao que foi desenvolvido durante os estágios, além das mudanças no perfil do bibliotecário, necessárias para atender as demandas da sociedade atual.

Para obtermos dados que atendessem a categoria (a) que trata da visão do bibliotecário quanto à relevância do estágio supervisionado no desenvolvimento de competências (competência em informação, técnicas, em gestão e comportamentais) solicitamos ao entrevistado que descrevesse suas considerações quanto ao valor do estágio supervisionado na sua formação. Quanto à categoria (b) que trata de quais competências foram desenvolvidas no estágio supervisionado utilizamos o questionário complementar, aplicado no final da entrevista, tentando correlacionar os diálogos as atividades práticas de rotina.

Para construção do questionário complementar elaboramos uma tabela embasada nos teóricos da pesquisa que tratam de competências técnicas, comportamentais (LEME, 2005), competência interativa e social, aplicadas à gestão de pessoas (BARBALHO, 2014), catalogação, classificação e organização de um acervo (MELLO, VIEIRA, 2012), competência em informação (FARIAS, BELLUZO, 2015). A partir do referencial teórico definimos questões que se enquadrassem em quatro tipos de competências conforme quadro 1.

Quadro 1- Competências do bibliotecário

\begin{tabular}{|c|c|}
\hline COMPETÊNCIA TÉCNICA & COMPETÊNCIA INFORMACIONAL \\
\hline $\begin{array}{l}\text { - } \quad \text { Faz uso de CDD na catalogação; } \\
\text { - } \quad \text { Faz uso de CDU na catalogação; } \\
\text { - } \quad \text { Faz uso Tabela de Cutter/PHA; } \\
\text { - Uso catálogo online na gestão do } \\
\text { acervo. }\end{array}$ & $\begin{array}{l}\text { - Desenvolveu e aplicou projeto cultural; } \\
\text { - Já se responsabilizou pelo desenvolvimento } \\
\text { de coleção? (seleção, aquisição, descarte); } \\
\text { - } \quad \text { Busca a informação via eletrônica utilizando } \\
\text { métodos variados; } \\
\text { - Teve que decidir pela implantação de } \\
\text { sistema automatizado. }\end{array}$ \\
\hline COMPETÊNCIA EM GESTÃO & COMPETÊNCIA COMPORTAMENTAL \\
\hline $\begin{array}{l}\text { - } \quad \text { Gerencia equipes; } \\
\text { - Já aplicou suas experiências de vida na } \\
\text { resolução de conflitos com usuário; }\end{array}$ & $\begin{array}{l}\text { - Já propôs um projeto que considerava } \\
\text { importante e foi negado pela chefia; } \\
\text { - Já mudou de trabalho por insatisfação com }\end{array}$ \\
\hline
\end{tabular}


- Teve que administrar algum conflito entre colaboradores;

- Recebe estagiários. as condições de trabalho;

- Prestou algum serviço autônomo;

- Realizou algum curso de capacitação antes de entrar mercado de trabalho.

Fonte: Elaborado pela autora com base nas referências citadas.

No questionário complementar, as questões foram dispostas de maneira aleatória, ou seja, misturamos competências técnicas, comportamentais, competências em informação e gestão de pessoas. A ideia foi captar naturalmente dos entrevistados, as atividades realizadas em seu ambiente de trabalho, e a forma como desenvolveu tais competências, se: durante o estágio, sozinho na prática, ou com outros profissionais. Depois de aplicarmos os questionários, partimos para a análise de dados, distribuindo as questões de acordo com o quadro acima, correlacionando cada atividade ao tipo de competência correspondente.

Dessa forma, se um entrevistado respondeu que faz uso de CDD nas atividades, e que aprendeu durante o estágio sob a orientação do bibliotecário, consideramos ser essa uma competência técnica mediada pela ação do orientador técnico, ou ainda, se o entrevistado ressaltou que aprendeu já no mercado de trabalho de forma autodidata. Correlacionar o questionário às entrevistas foi uma forma assegurar uma conexão entre discurso e prática, assim sucessivamente fomos atribuindo competências aplicadas na rotina de trabalho e detectando a forma como foram desenvolvidas.

No que se refere à categoria c) quanto às competências possíveis de desenvolver com a mediação bibliotecária, indagamos aos participantes sobre as contribuições do bibliotecário para sua formação profissional.E finalmente, para substanciar a categoria d) o ponto de vista dos bibliotecários sobre às competências exigidas no mercado atual, fizemos um consolidado do questionário complementar, buscando identificar as atividades mais citadas no desempenho de suas atribuições atuais. Além disso, durante a entrevista pedimos aos participantes que finalizassem sua participação com alguma reflexão sobre o que consideravam como competências imprescindíveis para quem almeja concorrer a uma vaga no mercado atual. Tais instrumentos subsidiaram nossa coleta de dados.

Após a construção dos instrumentos de coleta de dados, solicitamos à coordenação do curso de Biblioteconomia da UFC um relatório do Sistema Integrado de Gestão de Atividades Acadêmicas (SIGAA) dos bibliotecários formados no ano de 2005 e no ano de 2015. Utilizamos uma amostra intencional, considerando o que preceitua Richardson (1999) quando a escolha de sujeitos atendam as qualificações do público-alvo. No caso em questão, bibliotecários que estejam atuando no mercado, exercendo a profissão de bibliotecário. 
Um dos parâmetros para seleção foi saber se o potencial entrevistado estava exercendo a profissão atualmente. De uma lista de 59 formados, obtivemos retorno de 19, sendo que, desse total alguns não se enquadravam nas características da amostra intencional, por não estarem exercendo a profissão, logo desconsideramos: cinco que se encontravam na pós-graduação, uma estudando Direito sem trabalho ou outra atividade profissional no momento e duas trabalhando em outras áreas.

Assim, atuando na área, obtivemos onze potenciais entrevistados. Desse total, alcançamos êxito com oito bibliotecários (13,55\% da população inicial), os quais foram entrevistados entre 11 de setembro de 2017 e 22 de outubro de 2017. A outra parcela do público em potencial, ou seja, que atendiam aos parâmetros definidos, não foi entrevistado em virtude da dificuldade de agendamento com os referidos profissionais. O quadro 2 foi estruturado a partir do Formulário de Prospecção, o qual buscou identificar o perfil dos entrevistados.

Quadro 2- Perfil dos Entrevistados

\begin{tabular}{|l|l|l|l|c|c|}
\hline \multicolumn{1}{|c|}{ BIBLIO } & \multicolumn{1}{|c|}{ GÊNERO } & \multicolumn{1}{|c|}{ FUNÇÃO } & ÁREA DE ATUAÇÃO & IDADE & TEMPO DE AÇÃO \\
\hline B1 & F & Coordenadora de biblioteca & Mista & 37 & 11 anos \\
\hline B2 & F & Autônoma & Autônoma & 26 & 7 meses \\
\hline B3 & M & Bibliotecário & Mista & 24 & 17 meses \\
\hline B4 & F & Coordenadora de biblioteca & Escolar & 41 & 10 anos \\
\hline B5 & F & Bibliotecária & Especializada & 34 & 10 anos \\
\hline B6 & F & Bibliotecária & Mista & 34 & 10 anos \\
\hline B7 & F & Bibliotecária & Especializada & 24 & 20 meses \\
\hline B8 & F & Bibliotecária & Universitária & 34 & 09 anos \\
\hline
\end{tabular}

Fonte: Dados da pesquisa, 2017.

Percebemos que a maioria dos entrevistados está na faixa etária entre 25 e 35 anos, tendo somente um na faixa dos 40 anos, o que justifica um discurso inovador, senso crítico sobre a própria atuação e a necessidade de uma formação continuada, ou seja, tendo um novo olhar sobre ser o objeto de trabalho: a informação para o usuário conforme preceitua Figueiredo (2013).Quanto ao gênero, ainda se perpetua o estigma de profissão tipicamente feminina, o que pode mudar em um futuro próximo, considerando já termos atualmente uma significativa participação masculina no curso de Biblioteconomia na UFC.

\section{Análise e discussão dos resultados}


Tratar da participação do bibliotecário na formação do estudante de Biblioteconomia, durante o estágio supervisionado, exercendo uma mediação pedagógica, parte do entendimento que ele faz parte dessa construção, como mediador, consciente da sua parcela de responsabilidade no desenvolvimento profissional do discente. Quando dizemos "parcela" pretendemos deixar claro, que essa mediação carrega a semântica da concepção de Farias (2016, p. 107) quanto ao ato de mediar; ou seja, um ato de construção conjunta, com a participação ativa de orientador e estagiário. Podemos captar isso no discurso da maioria entrevistados:

[...] Às vezes eu tinha uma percepção, mas ela como já tinha um (sic) certo domínio da área me explicava, então me ajudou bastante. É uma troca, a gente aprende com eles as técnicas, mas eu também sinto que contribui com a minha vontade, porque quando a gente tá fazendo o curso, a gente tem tantos sonhos, tantos ideais, tantas coisas novas, então existe essa troca também [...] (B4)

Partindo do princípio de mediação como uma ação dialógica, selecionamos as duas últimas categorias estabelecidas para esta pesquisa para constar nesta comunicação, por entendermos que estão mais próximas do objetivo central da investigação. A categoria "influência do bibliotecário no desenvolvimento de competências" objetivou identificar o entendimento dos entrevistados quanto ao papel exercido pelo bibliotecário nessa fase considerada por alguns como "crucial", e, por vezes, só valorizada pelos estagiários quando já estão no mercado de trabalho, como descreveu B7:

O estágio supervisionado é de suma importância para o desenvolvimento de competências que serão necessárias quando estivermos atuando no mercado. Hoje, como bibliotecária de uma biblioteca especializada eu percebo como eu aprendi [ressalta] com as bibliotecárias que me supervisionaram. (B7) (grifo nosso).

Nessa perspectiva vimos que a experiência de B7, corrobora com o que Buriolla (2011, p. 13) pressupõe sobre o papel do estágio na formação do discente como "[...] o locus onde a identidade profissional do aluno é gerada, construída e referida; volta-se para o desenvolvimento de uma ação vivenciada, reflexiva e crítica [...]", e que podemos acrescentar se estenderá no seu perfil profissional no decorrer da carreira.

Como alerta Targino (2006), sabemos que ainda há profissionais atrelados às técnicas e a tecnologia, olvidando a responsabilidade social perante o fator humano, muitas vezes em virtude das múltiplas atribuições lhes conferidas de forma exacerbada, outras por ausência de senso crítico. Contudo, já podemos comprovar uma geração com uma nova perspectiva de ação:

No começo eu penei, sofri muito, assim, pela dificuldade, pelo desafio que era imenso [ressalta], hoje eu posso dizer assim, com a prática que a 
biblioteca escolar, talvez seja a mais abrangente... Porque você lida com professores, você lida com outros gestores, você lida com os alunos, tem que aprender a fazer projetos, você participa de eventos, então, assim é muito rica, eu me sinto privilegiada, é um desafio grande. (B4).

Para atender a tantas exigências da prática profissional, uma efetiva mediação pedagógica proporcionada pela participação do bibliotecário orientador na formação do discente de Biblioteconomia durante o estágio supervisionado, pode ser um diferencial amenizando os obstáculos futuros, através não somente do desenvolvimento de habilidades técnicas inerentes à profissão, mas dando uma segurança na tomada de decisão como nos relatou B5:

[...] Você cai no mercado um pouco insegura, mesmo que você tenha tido essas experiências, e se você não tiver tido essas experiências, piora consideravelmente né... Mas, aí, quando você vai pro(sic) mercado tendo passado por experiências profissionais principalmente pelo estágio supervisionado, te dar uma segurança maior. Eu sei fazer, eu pratiquei, então eu sei fazer sozinha.... Eu acho que é um conjunto, né... Não é só o orientador, não é só o bibliotecário, você também tem que ter esse papel também de fazer de buscar, praticar [...]. (B5)

Sabemos da relevância desse período tanto, pelo referencial teórico que nos apropriamos para fundamentar o estudo, quanto pelos discursos dos entrevistados, contudo, nesta fase focamos no profissional enquanto mediador de experiências, exemplos e ações que transcendem a fase de graduação e refletem no perfil do futuro profissional.

A primeira coisa que aprendi [...] foi como lidar com as pessoas. A percepção de que a gente deve atender a cada pessoa de forma justa, e reconhecer as diferenças de cada um. Modo de tratar cada um, o modo de falar com cada um. Questão da ética também [...]. O compromisso com a área, com o trabalho. (B1)

Buscando afinidade entre o relato das experiências vivenciadas no estágio, e sua atuação na gestão de pessoas, consideramos que a mediação bibliotecária relatada, surtiu um efeito positivo sobre o perfil da entrevistada, gerando um alinhamento entre teoria e prática gerencial de $\mathbf{B 1}$ :

[...] minha concepção de gestão, de uma boa gestão é muito particular! Pode ser que o meu tipo de gestão seja bom para uma equipe, pode ser que para outro grupo de pessoas, ele não seja funcional. Porque pessoas são muito variáreis, muito mutáveis... É preciso ter certo grau de maturidade pra (sic) compreender que cada pessoa tem um tempo de aprendizagem diferente do seu, e ter essa paciência de esperar que ela der o retorno, que você enquanto gestor está esperando naquele tempo devido [...] (B1).

Nosso entendimento quanto à harmonia entre o discurso e a prática de B1, foi sedimentada não somente no discurso da entrevistada, mas na observação do ambiente de trabalho, sua interação com os colaboradores e visitantes. Nessa mesma linha de raciocínio, ao 
compararmos as experiências de estágio de B5, ao seu ponto de vista, quanto ao desenvolvimento de competências, percebemos o quanto as experiências foram divergentes, ou seja, enquanto B1 teve uma participação efetiva de mediação durante o estágio, B5 vivenciou outros ambientes, outros perfis profissionais durante essa fase de aprendizagem, o que contribuiu para uma formação autodidata em muitas questões ressaltadas durante a entrevista.

Outras percepções que corroboram nosso entendimento quanto à relevância do mediador durante o estágio de B5, foi o fato de esta ser a única entrevistada, que não destacou o nome de um orientador técnico nesse período, e no relato das experiências há uma ressaltada colocação do "eu" como responsável pelo desenvolvimento de competências:

\footnotetext{
Quando eu cheguei aqui me disseram... Você vai reativar a revista. Só que eu não tinha conhecimento de periódicos, não conhecia nada de revista, não tinha ninguém para me ensinar [...]. Nada. Então eu fui buscar. Fui fazer curso pelo internet, sobre periódico científico, sobre processo de submissão, sobre a plataforma do IBCIT. Eu fui buscar bibliotecários que trabalhavam com essa ferramenta e com periódicos né? (sic). Fui atrás desses profissionais para me ajudar, me orientar. E aí eu fui fazendo [...]. (B5).
}

Ou seja, a autonomia foi necessária nessa oportunidade de trabalho, considerando que não havia uma equipe de colaboradores, contudo, entendemos que muito dessa postura diante dos obstáculos foi se formando a partir de lacunas experimentadas no período de estágio quando ela ressalta: “[...] Se eles não davam mais, é porque eles tinham uma limitação, eles podiam ir até certo ponto. E aí, eu acho que cabe ao estudante ir buscar! E era isso que eu fazia! [...]" (B5).

Isso nos remeteu aos estudos de psicologia de Ranganathan (1980) quanto à psicologia do intelecto para entender o comportamento do outro, a psicologia do interesse almejando detectar seus objetivos e a psicologia do indivíduo atentando para os complexos intrínsecos a todos nós, ora de inferioridade, ora de superioridade e outras vezes de traumas no decorrer de nossas experiências.

Diante dessas percepções ratificamos a relevância da participação do bibliotecário na formação do estudante de Biblioteconomia e entendemos que nessa relação há uma mediação na perspectiva de Almeida Júnior (2009) quanto a uma interferência por vezes racional, outras involuntárias, podendo não ser decisivo no perfil do futuro profissional, haja vista, a individualidade de cada ser. Entretanto, não podemos desconsiderar o quanto essa participação tem sido significativa para os que podem desfruta-la, sendo um diferencial que se estende para além do processo de graduação, fortalecendo as relações profissionais e a confiança nas próprias competências. 
Todos os entrevistados que tiveram participação efetiva do bibliotecário como orientador técnico, foram veementes em ressaltar a contribuição deste para sua formação profissional, desenvolvendo competências em informação adquirindo segurança na busca, recuperação e uso da informação - competências técnicas que as aulas teóricas introduzem e a prática consolida -, e, principalmente, as competências comportamentais que abarcam desde o respeito à cultura organizacional até a desenvoltura no trato com o público, e que agregam questões que se estendem por todos os âmbitos e fases da vida dos entrevistados.

Toda profissão abrange uma variedade de competências. Algumas fáceis de identificar e mensurar, outras descobrimos no decorrer das atividades, outras ainda, variam de acordo com o contexto organizacional, ou seja, não há fórmula definida quanto ao que apresentar no momento de uma entrevista, mas há alguns pré-requisitos que podemos identificar como fundamentais para concorrer a uma vaga. Esse foi o pressuposto para a definição da categoria " $d$ " as competências exigidas pelo mercado de trabalho.

Buscamos assim desvendar a partir da experiência dos bibliotecários "nativos" dessa realidade, indicações de questões imprescindíveis no contexto do mercado atual, considerando partir dos entrevistados, conhecedores da realidade presente, o referencial mais adequado das exigências mercadológicas.

As competências técnicas atinentes à profissão fazem parte das atividades bibliotecárias em qualquer ambiente, portanto, fica subentendido que não há o que ponderar quanto à capacidade de desenvolvê-las. A classificação, catalogação, indexação, o processamento técnico como um todo compõem o métier básico da profissão, variando os métodos, mas não o objetivo de organizar o acervo com o intuito de proporcionar ao usuário uma recuperação com rapidez e eficiência.

As outras competências que o mercado de trabalho exige são próprias das necessidades sociais que a hodiernidade exige. Segundo os entrevistados as mais relevantes são: gestão de pessoas, proatividade e uso de tecnologias. Ouvimos constantemente dos profissionais que partilham conosco suas experiências e aportes teóricos, o quanto a gestão documental de maneira informatizada tem se tornado um requisito básico para adentrar ao mercado de trabalho, já que o uso de sistemas em unidades de informação é uma realidade. Como ressaltou B1, “[...] a capacidade técnica de executar o gerenciamento eletrônico do acervo, é tão importante quanto à gestão de pessoas [...]".

Mesmo em ambientes informacionais que ainda não fazem uso de sistemas informatizados, devemos considerar que é uma questão de tempo e profissional adequado, para que todas as unidades de informação passem a utiliza-los na gestão informacional, pois há diversos sistemas abertos e gratuitos. Muitos entrevistados destacaram que as tecnologias 
de informação não podem ser vistas como uma ameaça ao profissional, mas como uma ferramenta que agrega valor e facilidades em qualquer atividade laboral, o que fortalece a necessidade de uma efetiva capacitação para o uso dessas ferramentas.

Apesar do projeto pedagógico do curso de Biblioteconomia conter a unidade curricular "Tecnologias da Informação", há uma lacuna nas disciplinas de processamento técnico quanto à realização de atividades práticas com sistemas de gestão eletrônica, principalmente no Sistema Pergamum utilizado pelo sistema de bibliotecas da UFC. Diante disso, as considerações de B7 referente a tais atividades é que durante sua formação:

[...] o déficit era muito grande, porque a classificação a catalogação era tudo muito manual, tudo no caderno, então a gente não tinha a interação com o sistema, com a automatização entendeu, não tinha interação com os campos do MARC. O que são os campos do MARC, né?. Você aprende, quem ensina isso? Não foi a minha professora. Não estou tirando o mérito não. Ela disse lá, mas é uma questão de decorar. Lá [no estágio], a gente tinha o livro novo, que chegou na biblioteca e que precisava ser incluído no Pergamum e que tinha lá todos os campos da CDD que eu tinha que colocar, principalmente no Pergamum que é muito completo [...] (B7).

O estágio remunerado ou supervisionado preenche essa lacuna da falta de familiaridade com os sistemas informatizados em sala de aula, já que atua nesse processo entre academia e mercado. Um momento de conhecer, manusear e tirar dúvidas na aplicação das teorias de classificação, indexação, ou seja, a catalogação visando à localização e recuperação da informação de maneira eficaz. Para tanto, a experiência do bibliotecário como mediador de experiências práticas é colocado por B7 ao relatar a experiência como estagiária e depois como orientadora técnica:

É diferente a atuação no campo [...] está em sala de aula, explicando o que é um estudo de usuário, e eu lá dentro da biblioteca aprender com o bibliotecário aprender como é que se dá um estudo de usuário. Como é eu vou fazer o estudo de usuário. Então, eu enquanto estudante, nós temos que aprender a valorizar [...]. Eu tive essa experiência já como bibliotecário, eu tive as duas coisas: tive estagiários que eram responsáveis, que valorizavam seu momento de estágio voluntário e tive aquele que por qualquer prova, trabalho e apresentação, coisas faltavam sem uma justificativa plausível, entende? Então eu vejo como eles tiveram um déficit na aprendizagem. Os que tiveram aqui comigo sempre. Por exemplo: eu tive dois que disseram: Ah, eu aprendi a catalogar aqui. Isso aconteceu comigo e eu pude repassar como mediadora [...] (B7).

A mediação bibliotecária fica clara no desenvolvimento dessa competência relevante para ingressar no mercado, no caso o uso das tecnologias, isso atrelado à proatividade discente em construir uma relação dialógica com o seu orientador técnico.Outra competência destacada pelos entrevistados, primordial para adentrar ao mercado, a gestão de pessoas, é fator de preocupação do projeto pedagógico, das atividades em sala, dos temores dos 
discentes e uma realidade nos ambientes informacionais, que não pode ser trabalhada no ambiente organizacional onde se realiza o estágio, por se tratar de uma atividade complexa que não cabe a um colaborador provisório e em formação (estagiário).

A gestão de pessoas dentro da unidade informacional é uma atribuição do gestor, resta ao discente à observação, como método de aprendizagem. Presenciar as tomadas de decisões bibliotecárias durante o estágio pode servir de norte para as futuras atividades do discente, como relatou B1 que declarou ter aprendido com sua orientadora durante o estágio: "[...] a ter maturidade para lidar com a equipe, para envolvê-los com um trabalho cooperativo, ao invés de você desenvolver uma gestão imperativa, fazer com que a equipe trabalhe junto com você [...]". Uma experiência que B1 aplica no bom desenvolvimento das ações atuais e que destaca como resultante de um bom trabalho em equipe.

Até aqueles que não exercem chefia diretamente em seus ambientes de trabalho, como B6 ressalta, há a necessidade de desenvolver tal competência, entendendo que a gestão de pessoas ocorre indiretamente nas relações com os colegas de trabalho, com os usuários. Ou seja, na forma de manifestar suas ideias, de gerar conflitos tão naturais de ambientes onde a diversidade de ideias e interesses precisa ser conduzida de forma equilibrada visando à harmonia e o bom andamento das atividades no ambiente organizacional:

[...] nem que a gente não queira o bibliotecário é um gestor também de pessoas. Muitas vezes, ele vai trabalhar numa biblioteca onde é só ele; só tem ele, então ele é o gestor. Às vezes diz: Não, mas eu não sou coordenador! Mas, nem que você não queira, mas você é! Quando acontece alguma coisa, algum problema é o bibliotecário que o diretor ou, quem for o superior na empresa, vai recorrer. Então nem que você não queira, você é gestor sim! (B6)

A gestão é uma atividade que requer conhecimento e maturidade e, mesmo que haja interesse do bibliotecário em inserir o estagiário nesse processo, a hierarquia organizacional não permitirá um desenvolvimento mais concreto dessa experiência, a não ser no caso de estágio remunerado, quando o vínculo com a instituição é mais prolongado e o discente é considerado um colaborador efetivo. Esses fatos podem justificar os números apresentados no Gráfico 1 que mostra as "competências em gestão desenvolvidas durante o estágio". 
Gráfico 1 - Competências em gestão desenvolvidas durante o estágio.

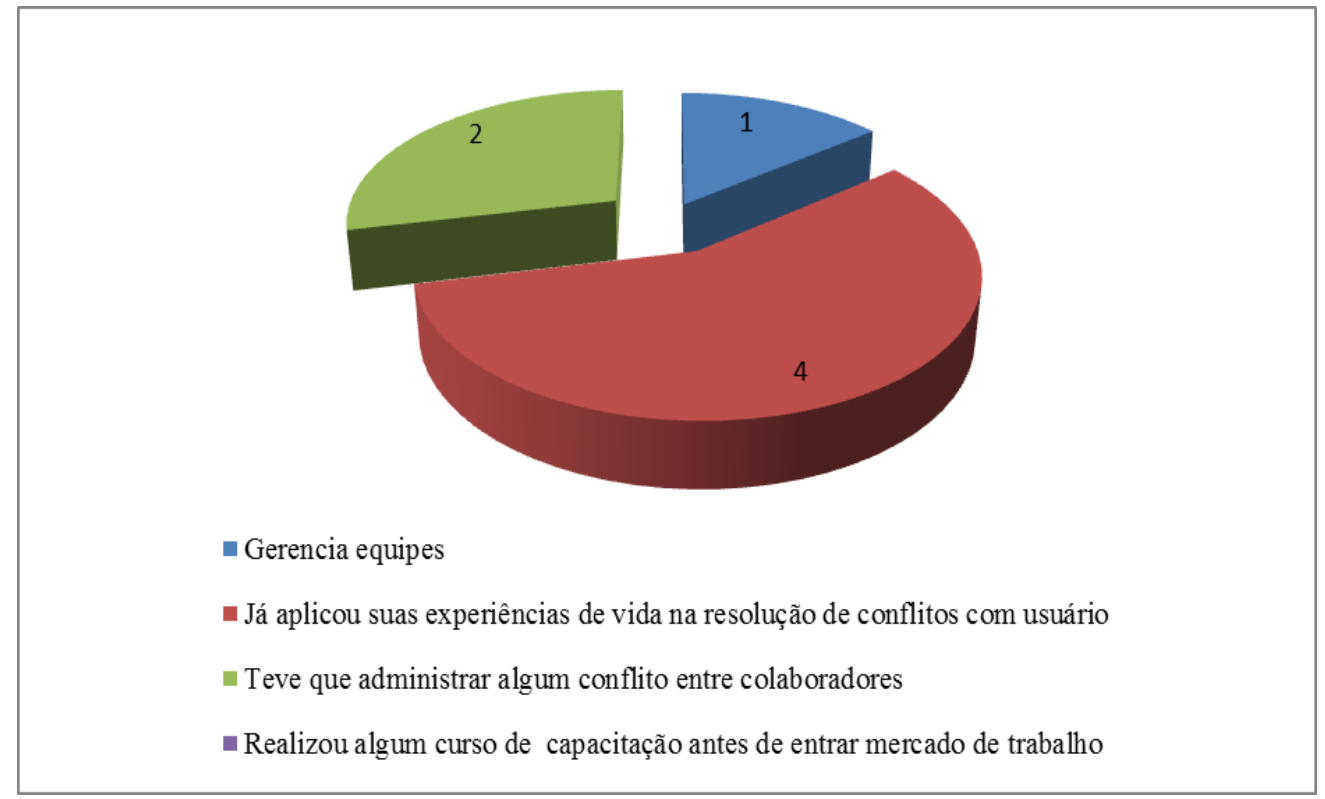

Fonte: Dados da pesquisa, 2017.

Diante da dificuldade de ação concreta, o discente pode se utilizar da observação do perfil do seu gestor para formar o seu próprio modo de gerenciar pessoas. Foi o que percebemos no depoimento de vários entrevistados, que se espelham em seus predecessores para desenvolverem uma gestão colaborativa e democrática.

Dessa forma, podemos considerar que apesar da importância da competência em gestão de pessoas para atender as demandas de mercado, o futuro profissional necessitará buscar uma formação continuada para um aprofundamento na área em questão. Para além da formação intelectual, o essencial é a capacidade de conviver de forma equilibrada com a diversidade de pensamentos, comportamentos e culturas, buscando o equilíbrio e a boa convivência no ambiente organizacional através da prática efetiva do respeito, da tolerância e da alteridade para com o outro. Além disso, a proatividade foi citada como requisito vital para o mercado de trabalho. Farias (2016), entende que para desenvolver tal competência é necessário um trabalho conjunto entre academia e o indivíduo em formação baseado na "[...] na conscientização, na ação e em metodologias que prezem por autonomia e criatividade, por mudanças nas estruturas mentais dos sujeitos por meio do diálogo [...]. (FARIAS, 2016, p. 118).

Nesta perspectiva, compreendemos que ser protagonista na universidade, no ambiente de estágio tornou-se uma condição fundamental para o discente e fator intrínseco para o seu desenvolvimento, ao buscar antecipar-se, vislumbrando soluções para as dificuldades diárias. Todavia, como citado anteriormente percebemos desde o início da formação um chamamento do discente por parte dos professores para o despertar dessa competência, assumindo um 
papel ativo no processo de aprendizagem, mas que frequentemente tem sido protelado, ou temido.

Durante as entrevistas buscamos constantemente ter em mente os conceitos de Bardin (1977) almejando inferir conexões entre discurso e ação dos entrevistados, e na questão da proatividade não foi diferente. Buscamos durante as conversas não fugir do roteiro de entrevista, mas aprofundar as descobertas e assim captar nas falas atitudes práticas de proatividade.

Constatamos então que a proatividade pode ter uma inerente do indivíduo, como ser extrovertido, ou tímido, mas precisa ser trabalhada, amadurecida nas relações com os outros, porque não se trata de impulsos intempestivos, mas de percepções sobre um determinado ponto crítico e antever uma solução. Entretanto, as soluções precisam ser construídas em conjunto, compartilhadas, remodeladas de acordo com as condições de concretização.

Apresentar uma ideia de melhoria no ambiente de trabalho é uma característica de alguém que buscar antecipar-se aos problemas, desenvolvendo um olhar mais amplo sobre o tempo e espaço de ação, não aguardando passivamente por uma crise para ser proativo. B4 exemplificou uma ação realizada em conjunto com seus colaboradores que ratifica esse entendimento. A catalogação realizada em qualquer biblioteca infantil dentro dos padrões de classificação da CDD em literatura infanto-juvenil será catalogada sob o código 028.5 ; ou seja, está em conformidade com os padrões de organização, podendo ser considerada adequada, contudo, B4 e sua equipe ampliaram suas percepções sobre ter o usuário como a razão de ser de qualquer ambiente informacional, não colocando a comodidade da gestão do acervo, acima da facilidade de acesso por parte do usuário.

Dessa forma, ratificando as ideias de Figueiredo (1992), Grogan (1995) e Targino (2006), quanto a ter o usuário como foco principal de uma unidade informacional, B4 e seus colaboradores aplicaram a proatividade no desenvolvimento de uma catalogação adequada ao nível intelectual dos usuários atendidos na biblioteca escolar:

[...] se você fosse organizar o acervo todo no 028.5, como é que você ia saber o que era para cada aluno... Pelos níveis de leitura? o que é para o infantil? O que é para primeira série? O que é para quarta e quinta? Então, aqui a gente criou uma coisa a mais que o 028.5. A gente criou sub-assuntos, então, e níveis de leitura. A gente tem três níveis de leitura, que é o leitor iniciante que é o Ll; infantil e primeiro ano, o LP- leitor em processo e LCleitor crítico [...]. (B4)

Antecipar-se aos problemas, ou vislumbrar estratégias de potencializar um serviço são ações efetivas de proatividade que podem fazer o diferencial na formação profissional desde o período acadêmico, e se assumidos pelo discente como propósitos de desenvolvimento 
pessoal certamente ao chegar ao mercado estarão mais fortalecidos para atender as exigências de mercado. B6 considera-se proativa no seu ambiente de trabalho quando "[...] traz o problema e já vem com uma proposta de solução [...]" (B6).

Durante a entrevista ela nos apresentou uma ação concreta a partir da percepção das dificuldades que a rodeia e das possibilidades de solução, apresentando um projeto em andamento sobre a ampliação do espaço da biblioteca. Segundo B6 a ideia do projeto foi dela, mas desenvolvida com a contribuição de outros profissionais, e ressaltou: "[...] não tô (sic) pedindo algo para o meu bel prazer, eu tô (sic) pedindo algo que vai ficar; eu posso me aposentar e o legado vai ficar para as gerações futuras [...]" (B6).

Outra entrevistada que considera a proatividade vital, não somente para entrar no mercado, mas principalmente para se mostrar como fator de melhoria contínua na instituição é B7, que ressalta a necessidade de:

[...] estar aberto, as novas possibilidades [...] Por exemplo: eu tenho que demonstrar isso, no meu dia a dia, Eu tenho que ser aquele bibliotecário que trabalha para fora da biblioteca e parece um discurso teórico, mas é verdade, nisso a teoria condiz com a prática que ver nossas possibilidades. [...] Dentro de uma instituição se a gente não for se adequar como estamos fazendo aqui agora, a elaboração de projetos, de atender meu diretor quando ele me pede prá (sic) trabalhar na instituição também... Eu vou passar... Eu vou ser vista com a profissional que não faz nada [...]. (B7)

A colocação de B7 condiz com a versatilidade necessária para se adaptar a única garantia da sociedade atual: a mudança constante. A mudança é uma característica inerente do ser humano, apesar de muitas vezes nos fecharmos para esta realidade é a mudança que impulsiona o ser humano a buscar o aperfeiçoamento seja através de formação continuada, ou de forma autodidata adaptar-se às mudanças é uma questão de sobrevivência. A proatividade é antecipar-se às mudanças, é mostrar-se como sujeito ativo e apto a mudar/adaptar-se. Antevendo lacunas a serem supridas e propondo soluções viáveis dentro do ambiente organizacional.

Entendemos que, a partir dos depoimentos coletados, a participação do bibliotecário como orientador técnico representa uma chave de acesso ao mercado, sendo um mediador ativo dessa passagem academia-mercado, e como tal deve ser valorizado, chamado ao diálogo para que essa parceria possibilite a formação de profissionais mais críticos, responsáveis por uma atuação mais dinâmica. Para isso, a rede de relações que se forma nos estágios deve ser considerada como a célula geradora de relações profissionais que podem contribuir com o desenvolvimento ou aprimoramento das competências de quem já está no mercado e de quem ainda vai chegar, através da continua troca de experiências. 


\section{Considerações finais}

A inquietação em conhecer as perspectivas do bibliotecário, desvendar os vínculos entre academia e ambiente profissional foi o cerne desta pesquisa, e o estágio supervisionado obrigatório considerado o fio condutor mais adequado entre esses dois universos. Buscamos identificar a importância do estágio supervisionado obrigatório para o desenvolvimento de competências exigidas pelo mercado, mas as contribuições dos entrevistados deram grande ênfase ao estágio remunerado, em virtude deste período que pode ser estendido por até dois anos permite ao estagiário uma imersão na cultura organizacional de forma mais profunda e duradoura, o que possibilita em alguns casos uma contratação imediata após a formação.

Para fundamentarmos a pesquisa nos moldes da ciência, buscamos alicerces teóricos da Biblioteconomia, mas principalmente sobre mediação e competências necessárias ao bibliotecário, além do estágio supervisionado. Tudo isso com o intuito de atender os objetivos propostos de identificar a ação mediadora do bibliotecário na formação do discente de Biblioteconomia.

Assim, para atender ao objetivo de identificar o papel do orientador técnico no desenvolvimento de competências dos estagiários, detectamos que a mediação do bibliotecário - enquanto orientador técnico no desenvolvimento de competências do discente durante o estágio - é considerada pela maioria dos entrevistados, como o principal fator de desenvolvimento das competências técnicas e de informação. Em relação às competências comportamentais e de gestão, a proatividade do estagiário tem um significativo destaque, o que corrobora com os pressupostos teóricos que identificam o ato de mediar como uma ação dialógica e dialética, ou seja, construída através do diálogo e da troca de experiências entre os sujeitos sociais.

A rotina nas instituições conveniadas permite uma vivência mais concreta com os profissionais e com a cultura organizacional, contribuindo para o desenvolvimento de redes de contato, as quais colaboram para que o discente mostre seu potencial e em muitos casos, seja contratado logo após a formação. Diante das falas de quem vivenciou a academia e atualmente exerce a profissão, obtivemos a certeza de que a contribuição bibliotecária na formação discente promove não somente a capacitação para as atividades técnicas essenciais profissão, mas também na formação de uma rede de contatos profissionais que possibilitam uma mediação continuada na troca de experiências.

Para delimitarmos o objetivo de identificar as principais competências exigidas atualmente, buscamos consolidar em um dos instrumentos de pesquisa as competências mais citadas pelos teóricos da área e através dos dados coletados, identificamos uma relação direta entre as exigências de mercado e as teorias compartilhadas pelos docentes. Assim, sem 
desconsiderarmos as peculiaridades de cada ambiente organizacional, as três competências mais visadas são: competência em gestão de pessoas, no uso de sistema informatizado na gestão do acervo e a proatividade. Esta última tem sido fator de destaque não somente para o mercado, mas desde a entrada na academia, instigando o discente a mudar sua posição de sujeito passivo na absorção do conhecimento repassado, para protagonista da própria formação, percebendo-se como coautor em qualquer processo de ensino aprendizagem, e esse chamamento se fortalece como uma necessidade essencial, para a construção de um perfil profissional que atenda as expectativas da sociedade. Tudo isso arquitetado sob os avanços tecnológicos que virtualizam atividades anteriormente realizadas de forma manual, e que atualmente precisam se adequar aos sistemas eletrônicos de gestão.

A gestão de pessoas é uma competência não obrigatoriamente exclusiva daquele que assume o papel de gestor na unidade informacional, mas essencial nas relações com a diversidade humana. A maturidade da tolerância e do respeito às diferenças tem se tornado uma questão vital em todos os âmbitos da sociedade e no contexto organizacional torna-se um diferencial competitivo. A proximidade dos discursos ratifica a necessidade de aproximar a academia do mercado através de ações que valorizem o potencial educador do bibliotecário, exercendo a mediação pedagógica, despertando no discente uma participação mais comprometida com a própria formação desde o início do curso, considerando que essa construção não pode aguardar a chegada ao mercado para percebê-la como fundamental.

\section{Referências}

ALMEIDA JÚNIOR. Mediação da informação e múltiplas linguagens. Pesquisa brasileira em Ciência da Informação, Brasília, v.2, n.1, p.89-103, jan./dez. 2009. Disponível em: http://inseer.ibict.br/ancib/index.php/tpbci/article/viewFile/17/39 Acesso em: 12 set. 2016.

BARBALHO, Célia Regina Simonetti. Gestão baseada nas competências. In: SEMINÁRIO NACIONAL DE BIBLIOTECAS UNIVERSITÁRIAS, 12., 2004, Recife, Anais eletrônicos... Recife: UFP, 2004.p. 3.

BARBALHO, Célia Regina Simonetti. Gestão baseada nas competências. Biblionline. João Pessoa, v. 10, n. 2, p. 97-107, $2014 . \quad$ Disponível em: http://periodicos.ufpb.br/ojs/index.php/biblio/article/view/16901/12484Acesso em: 20 out. 2016.

BARDIN. Laurence. Análise de conteúdo. Lisboa: Edições 70, LDA, 1977.

BURIOLLA, Marta A. Feiten. O estágio supervisionado. 7. ed. São Paulo: Cortez, 2011.

BRASIL. Ministério da Educação. Diretrizes Curriculares Nacionais dos cursos de Filosofia, História, Geografia, Serviço Social, Comunicação Social, Ciências Sociais, Letras, Biblioteconomia, Arquivologia e Museologia, 2001. Disponível em: <http://portal.mec.gov.br/cne/arquivos/pdf/CES0492.pdf>. Acesso em: 12 abr. 2016. 
FARIAS, Gabriela Belmont de; BELLUZZO, Regina Célia Baptista. Como desenvolver competência em informação mediada por modelagem conceitual-teórica: por uma aprendizagem significativa e criativa na educação. Londrina: ABECIN, 2015.

FARIAS, Maria Giovanna Guedes. Análise da produção, implementação e avaliação de um modelo de mediação da informação no contexto de uma comunidade urbana. 2014. $283 \mathrm{f}$. Tese (Doutorado) - Curso de Ciência da Informação, Instituto de Ciência da Informação, Universidade Federal da Bahia, Salvador, 2014. Disponível em: <http://repositorio.ufba.br/ri/handle/ri/16851>. Acesso em: 4 ago. 2016.

FARIAS, Maria Giovanna Guedes.Mediação e competência em informação: proposições para a construção de um perfil de bibliotecário protagonista. InCID: Revista Ciência da Informação e Documentação, Ribeirão Preto, v. 6, n. 2, p. 106-125, set. 2015/fev. 2016, p.117.

FIGUEIREDO. Nice Menezes de. A modernidade das cinco leis de Ranganathan. 1992. Ciência da Informação, Brasília,v. 21, n. 3, p. 186-191, set./dez. 1992. Disponível em:<http://revista.ibict.br/ciinf/article/view/430>. Acesso em: 22out.2016.

FREIRE, Paulo. Pedagogia do oprimido. 17. edição. Rio de Janeiro: Paz e terra, 1987.

GIL, Antonio Carlos. Métodos e técnicas de pesquisa social. São Paulo: Editora Atlas. 1999.

LEME. Rogério. Aplicação prática de gestão de pessoas: mapeamento, treinamento, seleção, avaliação, e mensuração de resultados de treinamento. Rio de Janeiro: Qualitymark, 2005, p. 3-83.

MELLO, Priscilla; VIEIRA, Ronaldo. O bibliotecário como agente cultural. São Paulo: AGBOOK, 2012.

MINAYO, Maria Cecilia de Souza. O desafio da pesquisa social. In: DESLANDES, Suely, GOMES, Romeu, MINAYO, Maria Cecilia de Souza. Pesquisa social: teoria, método e criatividade. Petrópolis, RJ: Vozes, 2013, p. 9-27.

RANGANATHAN, S. R. Psicologia e natureza do trabalho dos usuários. In: A contribuição da psicologia para o estudo dos usuários da informação técnico cientifica. Organização e tradução de Hagar Espanha Gomes. Rio de Janeiro, Calunga, 1980. p. 31-42.

RICHARDSON, R. J. et al. Pesquisa social: métodos e técnicas. São Paulo: Atlas. 1999.

SILVA, Jonathas Luiz Carvalho; FARIAS, Maria Giovanna Guedes. Abordagens conceituais e aplicativas da mediação nos serviços de informação. InCID: Revista de Ciência da Informação e Documentação, Ribeirão Preto, v. 8, n. 2, p. 106-123, out. 2017. Disponível em: <https://www.revistas.usp.br/incid/article/view/122628>. Acesso em: 20 nov. 2017.

TARGINO, M. das G. Olhares e fragmentos: cotidiano da biblioteconomia e ciência da informação. Teresina: EDUFPI, 2006.

UNIVERSIDADE FEDERAL DO CEARÁ. Departamento de Ciências da Informação. PP biblioteconomia_fortaleza.pdf. Disponível em: <http://www.ufc.br/ensino/cursos-degraduacao/187-biblioteconomia-fortaleza> 